\title{
Analysis of the Caulobacter crescentus Zur regulon reveals novel insights in zinc acquisition by TonB-dependent outer membrane proteins
}

\author{
Ricardo Ruiz Mazzon ${ }^{1}$, Vânia Santos Braz², José Freire da Silva Neto² and Marilis do Valle Marques ${ }^{1 *}$
}

\begin{abstract}
Background: Intracellular zinc concentration needs to be maintained within strict limits due to its toxicity at high levels, and this is achieved by a finely regulated balance between uptake and efflux. Many bacteria use the Zinc Uptake Regulator Zur to orchestrate zinc homeostasis, but little is known regarding the transport of this metal across the bacterial outer membrane.

Results: In this work we determined the Caulobacter crescentus Zur regulon by global transcriptional and in silico analyses. Among the genes directly repressed by Zur in response to zinc availability are those encoding a putative high affinity $A B C$ uptake system (znuGH), three TonB-dependent receptors (znuK, znuL and znuM) and one new putative transporter of a family not yet characterized ( $\mathrm{rrpM}$ ). Zur is also directly involved in the activation of a RND and a P-type ATPase efflux systems, as revealed by $\beta$-galactosidase and site-directed mutagenesis assays. Several genes belonging to the Fur regulon were also downregulated in the zur mutant, suggesting a putative cross-talk between Zur and Fur regulatory networks. Interestingly, a phenotypic analysis of the znuK and znuL mutants has shown that these genes are essential for growth under zinc starvation, suggesting that $C$. crescentus uses these TonB-dependent outer membrane transporters as key zinc scavenging systems.

Conclusions: The characterization of the C. crescentus Zur regulon showed that this regulator coordinates not only uptake, but also the extrusion of zinc. The uptake of zinc by C. crescentus in conditions of scarcity of this metal is highly dependent on TonB-dependent receptors, and the extrusion is mediated by an RND and P-type ATPase transport systems. The absence of Zur causes a disturbance in the dynamic equilibrium of zinc intracellular concentration, which in turn can interfere with other regulatory networks as seen for the Fur regulon.
\end{abstract}

Keywords: Caulobacter crescentus, Zur regulon, Zinc homeostasis, TonB-dependent receptor

\section{Background}

Zinc, as it occurs with other transition metals, entails a paradox to living cells. It is a scarce micronutrient in the environment, essential for a substantial number of biological processes [1]. On the other hand, despite not being a redox-active metal, in excess zinc may cause significant toxicity due to its high competitiveness relative to other divalent cations from the Irving-Williams series [2]. Thus, it is extremely necessary to maintain

\footnotetext{
* Correspondence: mvmarque@usp.br

'Departamento de Microbiologia, Instituto de Ciências Biomédicas, Universidade de São Paulo, Av. Prof. Lineu Prestes 1374, 05508-900 São Paulo, Brazil

Full list of author information is available at the end of the article
}

intracellular zinc levels under tight regulation. Bacterial zinc homeostasis is accomplished by a coordinated control of uptake, storage and export, which is mainly a result of controlled expression of import and export systems, each one governed by its own regulatory system [3].

A large number of bacteria regulate zinc uptake through Zur (Zinc Uptake Regulator), a regulatory protein belonging to the Fur (Ferric Uptake Regulator) family. This metalloprotein contains one structural zinc ion and a second one in its regulatory site per monomer, and acts as a repressor of genes coding for zinc uptake systems under zinc sufficiency $[4,5]$. More recently, it was showed that when loaded with metal in the regulatory site the protein may act as a direct repressor or activator binding to the promoter region of regulated genes 
[5]. The induction of extrusion systems is also a recurring response when zinc is in excess inside the cell. Two families of regulators, ArsR and MerR, were first described as the most important factors responsible for induction of these extrusion systems [4]. The P-type ATPase ZntA from Escherichia coli is regulated by the MerR-like transcriptional regulator ZntR [6]. CzrB from Staphylococcus aureus is a Cation Difusion Facilitator (CDF) involved in zinc extrusion that is regulated by CzrA, an ArsR-like transcriptional repressor [7]. More recently, other studies have reported that extrusion systems are also regulated in response to zinc in a Zur-dependent manner, as described for Xanthomonas campestris and Corynebacterium glutamicum [8-10].

Zinc enters the periplasmic space either via outer membrane non-specific porins or via TonB dependent receptors such as Neisseria meningitidis $\mathrm{ZnuD}$ and CbpA $[11,12]$, and in some cases the free metal may be sequestered by metalloproteins present in this compartment [1]. Once in the periplasm, zinc can cross the cell membrane through high affinity $A B C$ transporters such as ZnuABC in E. coli [13] and YciABC in Bacillus subtilis [14], broad-spectrum cation transporters like $\mathrm{MntH}$ in $E$. coli [15], metal ion transporters of ZIP superfamily such as ZupT in E. coli [16] or as a neutral metal phosphate through constitutively expressed inorganic phosphate uptake system (Pit) [17]. At least three types of transport systems have been described for the extrusion of zinc ions when in excess: P-type ATPases such as $E$. coli ZntA [18], RND (Resistance-Nodulation-Division) type exporters such as Alcaligenes eutrophus CzcABC [19] and CDF such as S. aureus ZntA [20].

Although zinc homeostasis has been extensively studied in a great diversity of bacterial groups, there are few studies in bacteria belonging to the group of $\alpha$ proteobacteria. The $\alpha$-proteobacteria group clusters organisms with widely different lifestyles. Within this group there are representatives of human and animal pathogens such as Rickettsia, Brucella and Ehrlichia, specimens of agronomic importance like Agrobacterium tumefaciens and many aquatic and marine species [21]. Considering the great importance of biological processes involving zinc carried out by bacteria of this group, such as photosynthesis in Rhodobacter sphaeroides [22] and virulence of $B$. abortus [23], understanding zinc homeostasis in $\alpha$-proteobacteria is highly relevant.

Caulobacter crescentus is a free-living and oligotrophic $\alpha$-proteobacterium widely spread through aquatic environments and very well adapted to utilize the scarce nutrients present in these environments. This bacterium has been extensively studied due to its finely regulated asymmetric cell division, which results in the generation of a stalked cell and a motile cell [24]. Genome sequence analyses of this bacterium have identified only two genes encoding transcriptional regulators belonging to the Fur family and 65 genes encoding TonB-dependent receptors [25]. Previous works from our group have studied the Fur regulator of $C$. crescentus, demonstrating that its regulon contains many transport systems involved in iron acquisition, including several TonB-dependent receptors [26,27]. Additionally, our group has characterized the LysR-type regulator CztR that activates the cell membrane transporter CztA, putatively involved in zinc acquisition [28].

In this work, we have investigated the contribution of the second regulator of the Fur family (here called Zur) for zinc homeostasis in C. crescentus via global transcriptomics analysis. The Zur regulon includes genes directly repressed by Zur encoding zinc uptake systems like high-affinity $\mathrm{ABC}$ transporters and TonB-dependent receptors, and a Zur-activated operon encoding an RND efflux system and a P-Type ATPase. Our results also indicate that in the absence of Zur there is an in vivo interference in the expression of some genes of the Fur regulon. Furthermore, we present experimental evidence that two zinc and Zur-regulated TonB-dependent receptors are essential for growth under zinc starvation, showing their importance for zinc uptake across the bacterial outer membrane.

\section{Results}

\section{Construction of a $C$. crescentus zur mutant strain}

There are two genes encoding transcriptional regulators belonging to the Fur family annotated in the C. crescentus genome: the well-characterized fur gene, involved in iron homeostasis [26,27] and CC0357, which could encode the zinc uptake regulator Zur. Alignment of E. coli, Yersinia pestis, X. campestris and Pseudomonas aeruginosa Zur proteins with the protein encoded by CC0357 shows sequence conservation in Zur-specific residues which are not shared with other members from the Fur family, like Fur and Nur [see Additional file 1: Figure S1]. This protein shares $46 \%, 43 \%, 45 \%$ and $47 \%$ identity with E. coli, $Y$. pestis, $X$. campestris and $P$. aeruginosa Zur proteins respectively. Based on these alignments and the experimental findings described throughout the text, we here call this protein Zur. To determine the role of this regulator in zinc homeostasis and C. crescentus physiology, a zur deleted strain (MM69), was obtained by allelic exchange. This strain showed growth rates in rich and minimal medium similar to the wild-type strain, and a $10 \%$ increase in intracellular zinc content (zur: $0.433 \pm 0.08 \mathrm{ppm} / w t$ : $0.392 \pm 0.09 \mathrm{ppm}$ ). Oxidative stress survival in MM69 strain was evaluated and no increased susceptibility to oxidative agents as hydrogen peroxide, pyrogalol, tert-butil hydroperoxide or paraquat was observed for the zur mutant in M2 medium (data not shown). 


\section{Determination of the Zur regulon using in silico and global transcriptomics analyses}

To identify the Zur regulon in response to zinc availability, total RNA from NA1000 (wild type) and MM69 was extracted $1 \mathrm{~h}$ after addition of $200 \mu \mathrm{M} \mathrm{ZnCl}$ to both cultures. The results showed that 28 genes had their expression altered in MM69, being 7 upregulated and 21 downregulated in the mutant (Table 1). Three genes included in Table 1 (CC0663, CC2720 and CC2722) were differentially expressed in the zur strain but did not fully attend the cutoff criteria; however, they were included because CC0663 presents a 100\% conserved in silico predicted Zur-binding sequence and CC2720 and CC2722 belong to the Zur-regulated putative operon CC2720-26. Upregulated genes include those potentially involved in zinc uptake, such as those encoding an ABC-2 type transport system here called znuGHI (CC1518-CC1519-CC1520), three TonB-dependent receptors here called znuK, znuL and znuM (CC1517, CC0214 and CC0663) and a hypothetical protein with six transmembrane domains (CC0320), that could be a putative zinc transporter (here called $z r p W$, for Zinc

\section{Table 1 Genes differentially expressed in the zur mutant}

\begin{tabular}{|c|c|c|c|c|}
\hline $\begin{array}{l}\text { Gene } \\
\text { number }\end{array}$ & $\begin{array}{l}\text { Gene } \\
\text { name }\end{array}$ & $\begin{array}{c}\text { Predicted Zur } \\
\text { binding sequence }\end{array}$ & Predicted function ${ }^{a}$ & $\begin{array}{l}\text { Fold change } \\
\text { (zur/wt) }\end{array}$ \\
\hline \multicolumn{5}{|c|}{ Upregulated } \\
\hline CC0214 & znul & TACGTTATTTCATAACAGT & TonB-dependent receptor & 5.02 \\
\hline CC0320 & zrpW & AATGTTACTTTATAACACG & Hypothetical protein (putative transporter domain) & 8.15 \\
\hline CC0482 & & & 5-methyltetrahydropteroyltriglutamate/homocysteine S-methyltransferase (EC:2.1.1.14) & 2.33 \\
\hline $\mathrm{CCO}^{2} 63^{\mathbf{b}}$ & znuM & CCTGTTACAGAATAACAGG & TonB-dependent receptor & 7.21 \\
\hline CC1517 & znuK & GATGTTATATCATAACAAT & TonB-dependent receptor & 41.30 \\
\hline CC1518 & znuG & ATTGTTATGATATAACATC & ABC-2 type transport system ATP-binding protein & 29.39 \\
\hline CC1519 & znuH & & ABC-2 type transport system permease protein & 38.09 \\
\hline CC1520 & znul & & ABC-2 type transport system permease protein & 11.61 \\
\hline \multicolumn{5}{|c|}{ Downregulated } \\
\hline CC0027 & & & PKHD-type hydroxylase (2OG-Fe(II) oxygenase superfamily) & 0.31 \\
\hline CC0711 & feoA & & Ferrous iron transport protein $\mathrm{A}$ & 0.45 \\
\hline CC1775 & & & Hypothetical protein (DUF2946 domain) & 0.37 \\
\hline CC1776 & & & Transcriptional regulator (GntR family) & 0.48 \\
\hline CC1777 & sodA & & Superoxide dismutase, Fe-Mn family & 0.23 \\
\hline CC1778 & & & TonB-dependent receptor & 0.44 \\
\hline CC1780 & & & ThiJ/Pfpl protease family protein & 0.50 \\
\hline CC1782 & & & Hypothetical protein & 0.47 \\
\hline CC2192 & & & Hypothetical protein (DUF3297 and Maf-like domains) & 0.44 \\
\hline CC2193 & & & Hypothetical protein & 0.48 \\
\hline $\mathrm{CC} 2720^{\mathbf{b}}$ & & GCCGTAATTAAGTAACAGA & $\begin{array}{c}\text { Hypothetical protein (Predicted periplasmic or external membrane component } \\
\text { protein with DUF2946 domain) }\end{array}$ & 0.46 \\
\hline CC2721 & CZrC & & RND system & 0.29 \\
\hline $\mathrm{CC} 2722^{\mathbf{b}}$ & $C Z r B$ & & RND system & 0.59 \\
\hline CC2723 & & & Hypothetical protein (Predicted periplasmic protein) & 0.46 \\
\hline CC2724 & CZrA & & RND system & 0.40 \\
\hline CC2725 & & & $\begin{array}{l}\text { Hypothetical protein (Predicted cytoplasmic membrane component } \\
\text { with DUF190 domain) }\end{array}$ & 0.38 \\
\hline CC2726 & $z n t A$ & & P-type ATPase & 0.31 \\
\hline CC2727 & & & Hypothetical protein (glutaredoxin domain) & 0.40 \\
\hline CC2927 & & & Hypothetical protein (PepSY-associated TM helix) & 0.41 \\
\hline CC2928 & & & TonB-dependent receptor & 0.46 \\
\hline CC3060 & & & Hypothetical protein (Predicted periplasmic protein with DUF2271 domain) & 0.50 \\
\hline CC3061 & & & Hypothetical protein (DUF4198 domain) & 0.41 \\
\hline CC3263 & $b f d$ & & Hypothetical protein (Fer2_BFD domain) & 0.28 \\
\hline
\end{tabular}

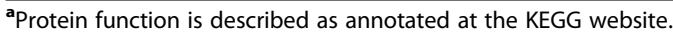

${ }^{\mathbf{b}}$ These genes had altered expression in the zur mutant but did not reach the cutoff criteria established for differentially expressed genes. 
Responsive Protein W). A zinc-requiring cobalaminindependent methionine synthase (CC0482) was also upregulated in the zur mutant.

Among the downregulated genes in the zur mutant, there are two large gene clusters, one containing genes for a GntR regulator, a Fe-Mn superoxide dismutase (SodA), a TonB-dependent receptor and hypothetical proteins (CC1775-76-77-78-80-82) and another cluster encoding an RND efflux system ( $c z r C B A$ ), a putative Ptype ATPase $(z n t A)$ and hypothetical proteins (CC272021-22-23-24-25-26). A 500-nt fragment upstream to $z n t A$ was cloned upstream to the $l a c Z$ reporter gene and that fusion showed no $\beta$-galactosidase activity, indicating the absence of a promoter; therefore we assumed that $z n t A$ is cotranscribed with the CC2720-25 putative operon (data not shown). All the other remaining genes (CC0027, CC0711, CC2192-93, CC2927-28, CC3060-61 and CC3263) were previously described as belonging to the Fur regulon and are organized in clusters that contain at least one gene predicted to be involved in iron acquisition [26,27] (Table 1).

To identify Zur-binding sites in the C. crescentus genome we performed two in silico analyses. Initially, a search using the motif GTTA-5 N-TAAC, conserved in Zur-binding sites of many proteobacteria was carried out. Only four putative Zur-binding sites with a 100\% conserved motif were retrieved, increasing to 53 when one-base pair change was allowed. Comparing this in silico analysis with the Zur-regulated genes identified in the DNA microarray analysis, we found that only five upregulated and one downregulated genes/operons have a predicted Zur-binding site located upstream to the annotated translation start site (Table 1). Separately, an $a b$ initio search, using the MEME tool with the upstream region of all Zur-regulated genes, identified the same six putative Zur-binding sites. Taken together, these data indicate that Zur directly represses five transcriptional units (CC0214, CC0320-21, CC0663, CC1517 and CC1518-1920) encoding putative zinc uptake systems, and directly activates one putative operon (CC2720-21-22-23-24-2526) encoding zinc efflux systems (Table 1). Most of the remaining genes downregulated in the zur mutant are not preceded by a predicted Zur-binding site and belong to the Fur regulon, suggesting that they are indirectly activated by Zur (see Discussion below).

\section{Validation of the zinc and Zur-regulated genes}

To validate the Zur-regulated genes obtained in the microarray and in silico approaches, the regions upstream to the annotated start codons were amplified by PCR and cloned upstream to a lacZ reporter gene. Plasmids containing the transcriptional fusions were introduced into both the NA1000 and MM69 strains. $\beta$ galactosidase assays were performed in minimal media supplemented with $500 \mu \mathrm{M} \mathrm{ZnCl}_{2}, 500 \mu \mathrm{M}$ EDTA (simulating zinc depletion) or $500 \mu \mathrm{M}$ of both (Figure 1). According to this assay, the expression driven by the promoters of $z n u K, z n u L, z n u M, z r p W$ and $z n u G H I$ increased in the zinc depletion condition triggered by EDTA and were derepressed in the zur mutant strain. The expression of these genes returned to the levels shown in the presence of zinc when both EDTA and $\mathrm{ZnCl}_{2}$ were added in NA1000 but not in the zur mutant, indicating that these genes are repressed by Zur in the presence of zinc, validating the microarray data. Complementation of the zur mutation with a copy of the $z u r$ gene in trans (plasmid pUJ-zur) restores the repression under excess zinc (Figure 1).

The same fragments containing the gene promoters described above were used in EMSA with the C. crescentus purified His-FLAG-Zur protein (Figure 2). According to the results, Zur was able to bind in vitro to the promoter of $z n u K / z n u G H I, z n u L, z n u M$ and $z r p W$, and the probes presented shifted mobility with addition of even the lowest concentration of Zur (25 nM). The specificity of Zur binding was demonstrated by absence of shift when the probe containing the coding region of the stationary phase-induced gene $\operatorname{csp} D$ was used, even at the highest Zur concentration $(1 \mu \mathrm{M})$. Moreover, competition with excess unlabeled specific probe caused a complete loss of shift, which was not seen when excess of unlabeled nonspecific probe was added.

The transcriptional lac $Z$ fusion containing the promoter region of the $c z r C B A$ operon (CC2721, CC2722 and CC2724), encoding an RND efflux system, three hypothetic proteins (CC2720, CC2723 and CC2725) and the P-type ATPase ZntA (CC2726) (Figure 3A) was previously available [29]. The expression of lac $Z$ driven by this promoter was low in cultures grown in M2 medium or M2 containing $500 \mu \mathrm{M}$ EDTA and increased in the presence of $500 \mu \mathrm{M} \mathrm{ZnCl}$ or $500 \mu \mathrm{M}$ of both (Figure 3B). Moreover, expression of this construct is very low in the zur mutant, indicating that this operon is activated by Zur in presence of zinc, validating the microarray data.

The same fragment containing the CC2720-26 promoter was used in an EMSA with $C$. crescentus purified His-FLAG-Zur protein. However, it was not possible to see in vitro Zur binding to the DNA probe containing this promoter. In an attempt to determine whether the predicted Zur-binding site of the CC2720-26 promoter was functional and if Zur regulates this operon directly, site-directed mutagenesis was performed. The first half of the conserved motif of the predicted Zur-binding site was changed from GTAA to ACCG, leaving unchanged the remaining of the binding sequence (Figure 4A). This DNA fragment was cloned upstream to the lac $Z$ reporter gene and introduced into NA1000 and MM69 strains. This change in sequence led to a decrease in the 

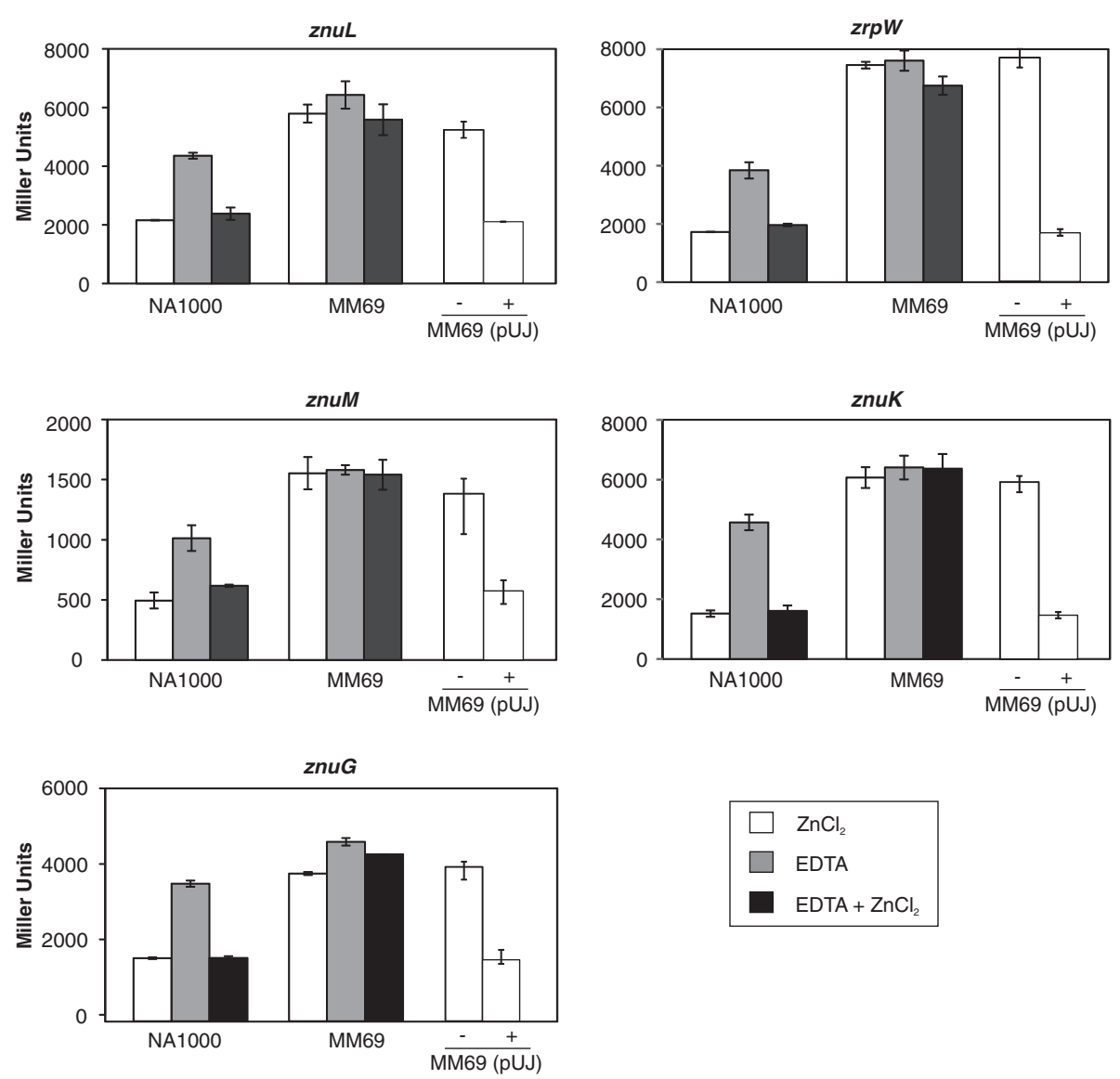

Figure 1 Influence of Zur and zinc availability in the expression of Zur-repressed genes. Transcriptional fusions of znuK, znuL, znuM, zrpWX and znuGHI promoter regions to the lacZ reporter gene were introduced into NA1000, MM69, MM69 (pUJ) and MM69 (pUJ-zur) strains, and grown under different regimens of zinc availability. Expression was determined by $\beta$-galactosidase activity assays. White bars indicate M2 medium supplied with $500 \mu \mathrm{M} \mathrm{ZnCl}$, light grey bars indicate M2 medium supplied with $500 \mu \mathrm{M}$ EDTA and dark grey bars indicate M2 medium supplied with $500 \mu \mathrm{M} \mathrm{ZnCl} 2$ and $500 \mu \mathrm{M}$ EDTA. In the complementation analysis, MM69 strain harboring plasmid pUJ142 without insert (-) or carrying the zur gene $(+)$ was used. The results shown are the average of at least three experiments. Error bars indicate standard deviations.

expression in NA1000 to levels similar to those observed with the wild-type promoter in MM69, making it also unresponsive to zinc (Figure 3B). These results confirmed that the predicted Zur binding site in the regulatory region of CC2720-26 operon is necessary for its regulation in response to zinc ions, likely by direct Zur binding. This was further confirmed by complementation with the zur gene in trans, which restored the expression pattern observed in the wild type (Figure 3C).

By analyzing the regions upstream of the initiation codons of the validated genes and taking into account the transcription start sites determined by [30], it was possible to predict the positions of the -10 and -35 promoter sequences of these genes. Several of these genes were described as having two promoters, one responding to the cell cycle and the second one to metal stress [30], agreeing with the zinc-dependent regulation observed in this work. The positions of the Zur-binding sites in these regulatory regions are shown in Figure 4A. In znuK, $z n u L$ and $z n u G H I$ the Zur operator overlaps the -10 region, while in $z r p W$ and $z n u M$ it is located between the -10 and -35 elements. These locations of the Zur operators agree with Zur acting as a repressor of the expression of these genes, confirming the data obtained with the microarray and $\beta$-galactosidase assays. Oppositely, in the CC2720-26 promoter region, the putative Zur binding sequence is upstream of the -35 promoter element, agreeing with Zur acting as an activator, data also supported by the previous assays. Alignment of the sequences present in the promoter regions of $z n u L, z r p W, z n u M$, znuK/znuGHI genes and CC2720-26 operon revealed that the C. crescentus Zur-binding site is an inverted repeated sequence with two conserved blocks (Figure 4B and C).

\section{Importance of the Zur-regulated TonB-dependent receptors} ZnuK and ZnuL for zinc scavenging

Among the eight genes upregulated in the zur mutant, identified from both microarray analysis and in silico 


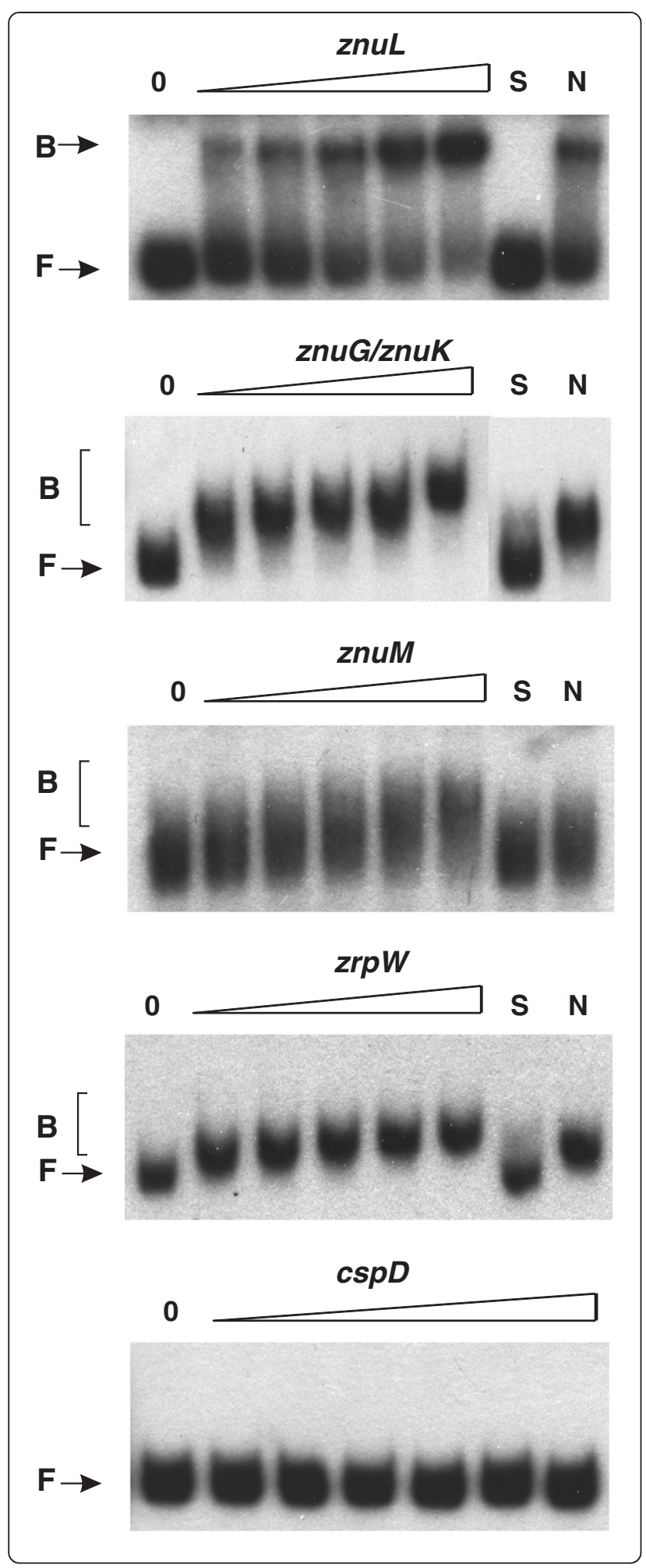

Figure 2 Zur binding to the regulatory regions of Zur-repressed genes. DNA fragments corresponding to the promoter regions of znuL, znuM, zrpWX and znuK/znuGHI and the coding region of CspD were labeled with ${ }^{32} \mathrm{P}$ and incubated or not with increasing concentrations of purified His-FLAG-Zur (0, 25, 50, 100, 200, 500 and $1000 \mathrm{nM}$; this latter concentration was used only for cspD). Competition assays were carried out with $0.2 \mu \mathrm{M}$ of purified His-FLAG-Zur in the presence of 30-fold of unlabeled probe (S) or in the presence of 30-fold of non-specific competitor (N). The non-specific competitor probe was the coding region of the stationary phase-induced gene cspD. Free probe and His-FLAG-Zur bound probe are indicated by $(\mathrm{F})$ and (B), respectively.

screening, three encode putative TonB-dependent receptors (znuK, znuL and $z n u M)$. Mutant strains for $z n u K$, $z n u L$ and CC0815 [31] were analyzed, this last one being a gene encoding for a TonB-dependent receptor not responsive to zinc or iron and used as control. All strains were then grown under different conditions of zinc availability, in order to determine the role of ZnuK and ZnuL in zinc uptake (Figure 5).

All mutant strains showed growth rates similar to those of wild-type and zur strains in minimal M2 medium (data not shown) and also showed no significant differences in colonies size on M2 agar plates (Figure 5A and $\mathrm{B}$ ). When EDTA was added to the medium up to a final concentration of $500 \mu \mathrm{M}$, znuK and $z n u L$ mutant colonies were smaller than wild-type and zur colonies, suggesting slower growth rates in this condition. Additionally, when EDTA concentration was raised up to $850 \mu \mathrm{M}$, only wild-type, MM78 (CC0815) and the zur strains were able to form colonies after a 5day incubation, with the zur mutant showing larger colonies than NA1000, suggesting that derepression of the zinc uptake systems benefits the zur mutant strain under extreme zinc limitation condition. The addition of $\mathrm{ZnCl}_{2}$ to the plates containing $850 \mu \mathrm{M}$ EDTA restored growth of the $z n u K$ and $z n u L$ strains, confirming that growth was prevented by the absence of zinc (Figure 5A). Besides that, the ability of MM78 to grow under severe zinc deprivation indicates that the phenotype seen in $z n u K$ and $z n u L$ mutant strains is not a general or unspecific result but instead is a specific effect of zinc uptake impairment (Figure 5B). Complementation of each mutation with the respective gene in trans restored the ability of growing in $850 \mu \mathrm{M}$ EDTA (Figure 5B). Interestingly, a cross-complementation with the other gene also allowed growth under these conditions, suggesting that an increased expression of one TonB-dependent zinc transporter may compensate for the lack of the other one.

\section{Discussion}

In this paper, we studied the Zur protein from C. crescentus, identified several zinc and Zur-regulated genes and characterized two novel TonB-dependent receptors 
A

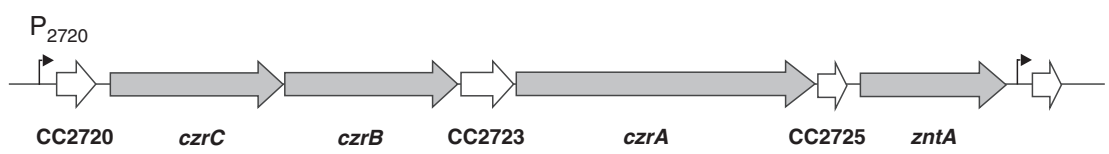

B

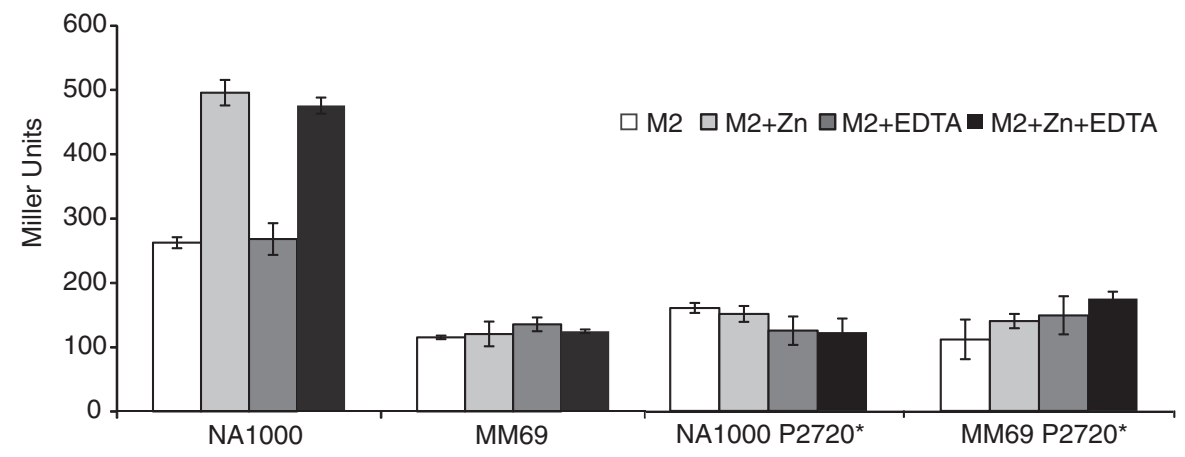

C

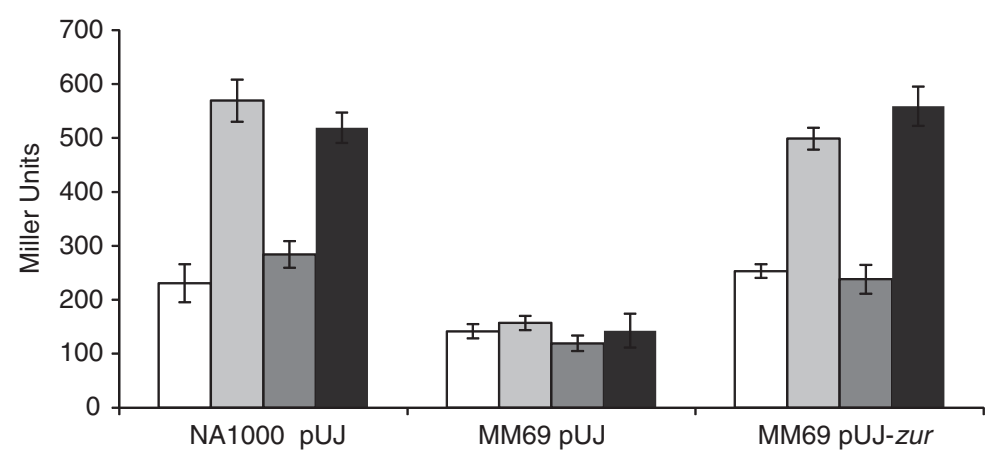

Figure 3 Role of Zur in the expression of the CC2720-26 operon in response to zinc. (A) Scheme of C. crescentus CC2720-26 locus depicting the putative czrCBA operon organization described in [29]. Gray arrows indicate genes encoding the RND and P-type ATPase transport systems. White arrows indicate hypothetical proteins. (B) $\beta$-galactosidase activity assay of CC2720-26 operon in response to zinc availability, in NA1000 (wild type) and MM69 (zur mutant) strains. White bars, M2 medium, light grey bars, M2 containing $500 \mu \mathrm{M} \mathrm{ZnCl}$, dark grey bars, M2 containing $500 \mu \mathrm{M}$ EDTA and black bars, M2 containing both $500 \mu \mathrm{M} \mathrm{ZnCl}$ and $500 \mu \mathrm{M}$ EDTA. Asterisks indicate that the putative Zur binding site into the promoter region of CC2720-26 was mutagenized. The results shown are the average of at least three experiments. Error bars indicate standard deviations. (C) $\beta$-galactosidase activity assay of CC2720-26 operon in response to zinc availability in NA1000 and MM69 strains harboring plasmid pUJ142 containing or not the zur gene.

involved in zinc acquisition. According to the DNA microarray data and in silico analysis we defined that the C. crescentus Zur regulon is composed by genes mainly involved in uptake and efflux of zinc. The results obtained from EMSA and $\beta$-galactosidase assays show that Zur binds directly to the regulatory regions of $z n u G H I$ (ABC transport system), znuK, znuL, znuM (TonBdependent receptors) and $z r p W$ (putative transporter). Zur acts repressing these genes in the presence of zinc but when this metal is scarce Zur is released from the operators liberating transcription to increase production of zinc uptake systems. Conversely, Zur activates transcription of the CC2720-26 operon in condition of high zinc concentration, allowing expression of the
RND and P-type ATPase efflux systems. It was previously demonstrated that the RND system encoded by $c z r C B A$ is essential for growth in the presence of added zinc or cadmium $[29,31]$.

Studies performed with many other bacteria have already described that high affinity- $\mathrm{ABC}$ transport systems are regulated by Zur and, more recently, studies using transcriptomics analysis $[8,32,33]$ and proteomics [11] approaches identified TonB-dependent receptors regulated by Zur in response to zinc, but only the two TonB-dependent receptors from Neisseria meningitidis have been characterized as zinc uptake systems [11,12]. There are few cases described in which Zur acts as a positive regulator of extrusion systems. This ability was 


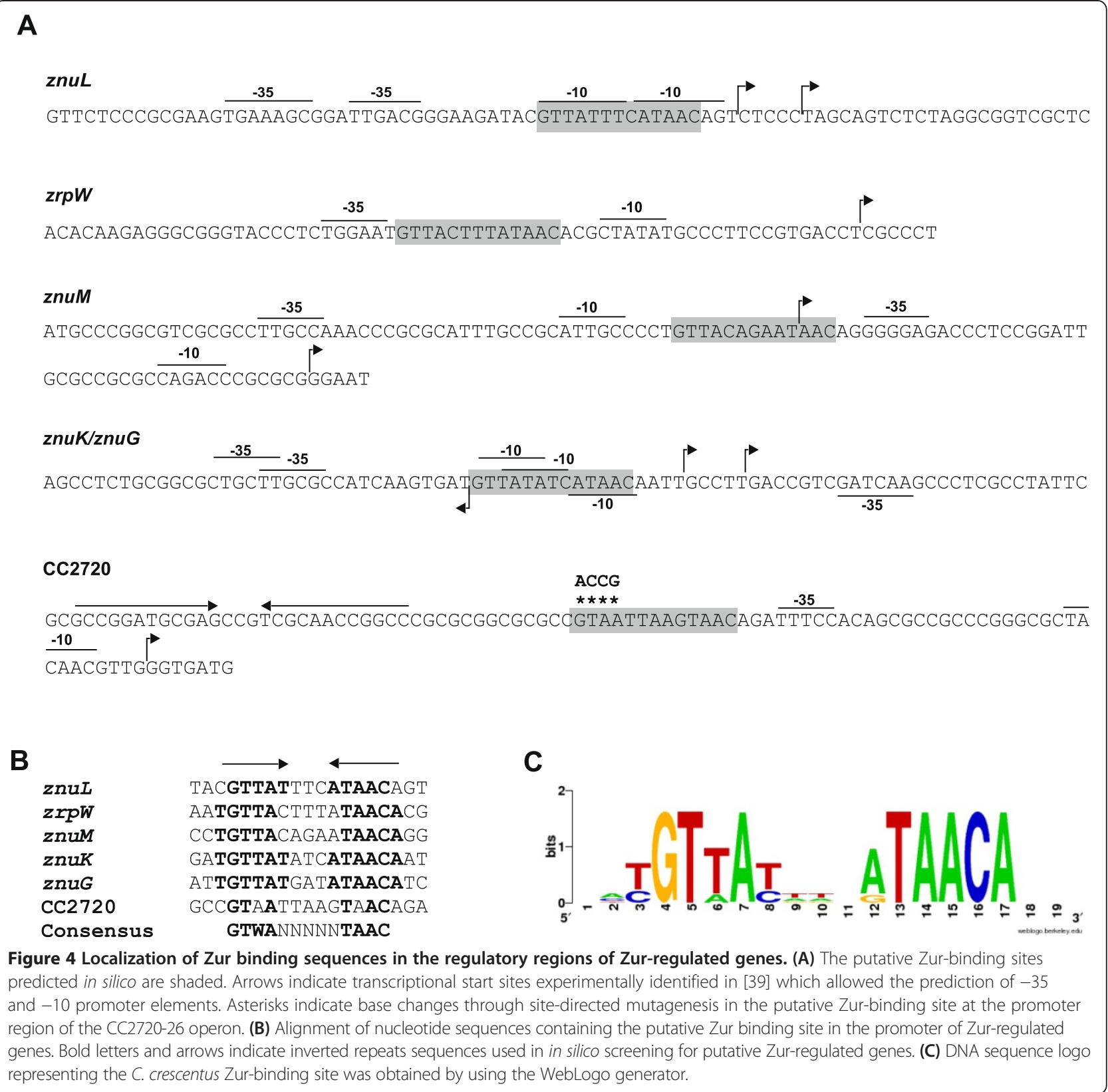

first described for Zur from X. campestris [08] and later for C. glutamicum [09]. Hence, as in those bacteria, Zur is a transcription factor responsible for direct regulation of both zinc uptake and extrusion in C. crescentus.

It was not possible to obtain in vitro binding of Zur to the promoter of CC2720-26 operon, but the existence of a Zur-binding site on this promoter was confirmed by site-directed mutagenesis. Although all Zur-binding sites in promoters of Zur-repressed genes overlapped the promoter elements as typically observed for transcriptional repressors, the position of the Zur-binding site in CC2720-26 was upstream of the -35 promoter element in agreement with its role as a positive transcriptional regulator. In the regulatory region of $\mathrm{CC} 2720-26$ there is an imperfect inverted repeat 11-4-11 (GCCGGATGCGA4 N-TCGCAACCGGC) located 13 nt upstream of the Zur-binding site. In $X$. campestris, Zur activates a gene encoding a transporter belonging to the CDF family in response to zinc, and an imperfect inverted repeat of 20-bp is found on the promoter region which is essential for binding of Zur both in vivo and in vitro, indicating that Zur recognizes simultaneously that inverted repeat and the Zur binding sequence [08]. We speculate that the inability of $C$. crescentus Zur to bind the CC2720-26 


\section{A}

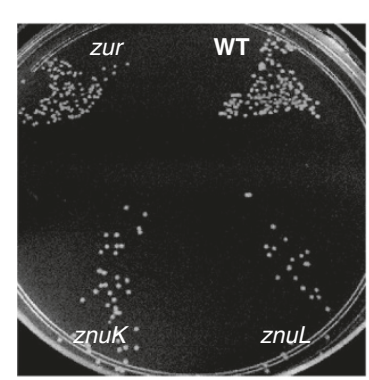

$850 \mu \mathrm{M}$ EDTA

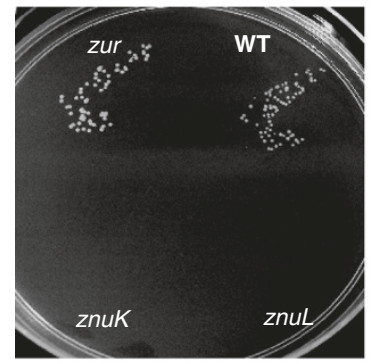

B

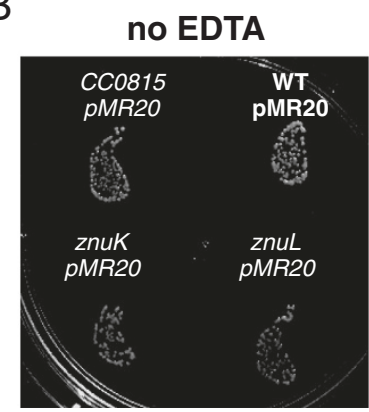

$500 \mu \mathrm{M}$ EDTA

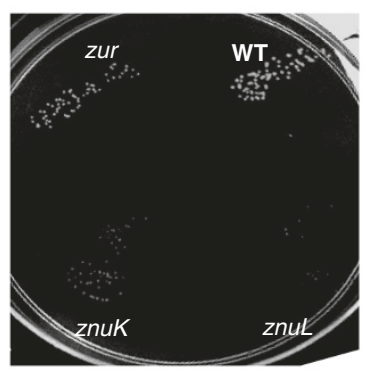

$850 \mu$ M EDTA

+ $1.7 \mathrm{mM} \mathrm{ZnCl}_{2}$

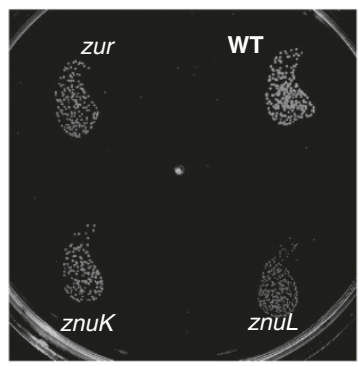

$850 \mu \mathrm{M}$ EDTA

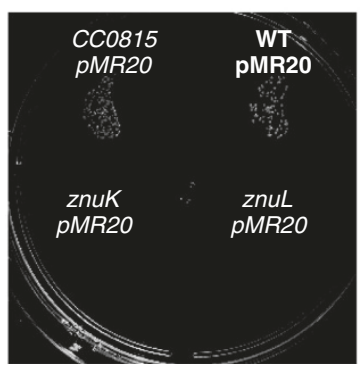

$850 \mu \mathrm{M}$ EDTA

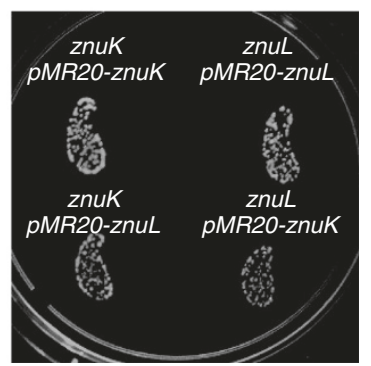

Figure 5 Contribution of znuK and znuL genes for growth in zinc deprivation. (A) Growth of NA1000, zur, znuK and znuL mutant strains under different regimens of zinc availability. Aliquots of $20 \mu \mathrm{L}$ from a $10^{-5}$ dilution of cultures were plated on $\mathrm{M} 2$ medium without or with addition of $500 \mu \mathrm{M}$ EDTA (3 days growth), $850 \mu \mathrm{M}$ EDTA (5 days growth) or $850 \mu \mathrm{M}$ EDTA and $1.7 \mathrm{mM} \mathrm{ZnCl} 2$ (3 days growth). (B) Growth of NA1000, CC0815::mini-Tn5, znuK::mini-Tn5 and znuL::mini-Tn5 strains harboring plasmid pMR20 containing or not the genes indicated. Aliquots of $20 \mathrm{\mu L}$ from a $10^{-5}$ dilution of cultures were plated on M2 medium containing tetracycline $\left(1 \mu \mathrm{g} \mathrm{ml}^{-1}\right)$ and the same additions as in (A).

promoter in vitro could be due to the requirement for an accessory protein that binds to the inverted repeat sequence and stabilizes Zur binding.

In addition to the genes directly regulated by Zur, microarray and in silico analysis revealed that most of the genes downregulated in MM69 strain with no predicted Zur-binding sites belongs to the Fur regulon, being repressed by iron-bound Fur in the presence of iron [26]. One hypothesis to explain these results is that in the zur mutant background the increased intracellular zinc concentration could result in mismetallation of Fur by zinc ions and the zinc-bound Fur protein could be inappropriately repressing Fur-regulated genes in an ironindependent manner. Indeed, it has already been shown that Fur bound to other divalent cations as zinc, cobalt and manganese preserves the ability of binding to DNA in vitro with almost the same affinity than the ironbound Fur $[34,35]$. An example that zinc may metallate Fur in its regulatory site is the crystal structure of the Fur protein from Pseudomonas aeruginosa where the regulatory site was occupied by a zinc ion instead of an iron ion [36]. Therefore, our results suggest cross-talk between Zur and Fur caused by an unbalance in zinc levels in the zur mutant, which corroborates previous findings that metal ion selectivity can be disturbed among metalloregulators of the Fur family [35,37].

Remarkably, the C. crescentus Zur regulon does not contain genes encoding ribosomal proteins. It has been 
proposed for B. subtilis [38,39], X. campestris [08], Yersinia pestis [22], Mycobacterium tuberculosis [40], N. meningitidis [32] and inferred via in silico analysis for several other organisms [41] that some ribosomal proteins could act as a zinc reserve. In conditions of zinc deficiency, their expression would be repressed in detriment of its paralogs that did not use zinc in their structure. C. crescentus does not have paralogs of genes encoding these ribosomal proteins, indicating that this mechanism is not used. However, despite the fact that in C. crescentus ribosomal proteins are not Zur-regulated, we cannot exclude the possibility that they might still act as intracellular zinc reserves under control of another zinc regulator. The zinc and Zur-repressed gene zrpW, encoding a putative transporter, is likely cotranscribed with CC0321 (zrpX). The hypothetical protein $\mathrm{ZrpX}$ has two conserved CobW domains in the $\mathrm{N}$ - and $\mathrm{C}$ - terminal portions. This protein belongs to COG0523 family which in some cases was observed to be Zur-regulated. It is believed that proteins belonging to the Zur-regulated subfamily of COG0523 family may perform metallochaperone functions related to intracellular traffic and storage of zinc [42]. Thus, in $C$. crescentus $\mathrm{ZrpX}$ could be an alternative to the ribossomal proteins as a zinc reserve.

According to previous and current data it is likely that Zur is not the solely responsible for zinc homeostasis in C. crescentus. The putative zinc transporter CztA and its regulator CztR previously identified [28] are zinc responsive and not regulated by Zur. Moreover, the $n c z C B A$ RND system involved in zinc extrusion is upregulated in response to zinc [29] also in a Zur-independent manner. Genome analysis predicts the existence of other transcriptional regulators from the ArsR/SmtB and MerR families, already described as involved in the regulation of genes for metal extrusion in other organisms [06, 07, 25]. Further studies with global approaches might elucidate the role of these regulators in zinc homeostasis.

As Zur represses the expression of zinc uptake systems and activates the expression of two efflux systems, there should be an accumulation of intracellular zinc in the zur mutant. Indeed, strain MM69 showed 10\% more intracellular zinc content than wild-type (normalized to dry mass), which may be a result of constitutive uptake and low efflux in the absence of Zur. However, it must be taken into account that $C$. crescentus NA1000 encodes in its genome seven RND systems, two CDF proteins and three P-type ATPases [25,43] which also may have some role in zinc efflux. A second RND system, $n c z C B A$ - which is not Zur-regulated - is induced in zinc excess and the $n c z A$ mutant showed impaired growth in the presence of $130 \mu \mathrm{M} \mathrm{ZnCl}_{2}$ [29]. Therefore, it is possible that the zur mutant strain did not show a more pronounced accumulation of intracellular zinc because other efflux systems as $n c z C B A$ may be eliminating zinc.
Many nutrients and ions can cross the bacterial outer membrane and enter into the periplasmic space through passive transport via porins. However, when the concentration of an ion is very low outside, diffusion becomes unfavorable. Thus, TonB-dependent receptors can play a crucial role in the uptake of scarce metals. Although the role of these proteins in iron-complex uptake is welldefined, little is known about others metals [44], with only few reports describing the role of TonB-dependent receptors in the uptake of nickel and zinc $[11,12,45]$. In this work, we presented experimental evidence that two out of the three Zur-regulated TonB-dependent receptors, ZnuK and ZnuL, are important for C. crescentus growth under zinc deprivation. Moreover, cross complementation analysis showed that there seems to be a functional redundancy between $z n u K$ and $z n u L$, which will be further investigated. Since $C$. crescentus is welladapted to poor nutrient conditions, and has three receptors of this type as opposed to only one in pathogenic $N$. meningitidis, the uptake of zinc would be less strongly impaired by the absence of a single transporter.

\section{Conclusions}

This work has characterized the regulon of Zinc Uptake Regulator (Zur) of Caulobacter crescentus by means of transcriptomics and in silico analyses. The Zur regulon comprises genes encoding transport proteins, such as ABC transporters, TonB-dependent receptors, an RND system and other putative transporters. Our results showed that Zur can act both as a repressor of genes for zinc uptake (znuK, znuL, znuM, znuGHI and $z r p W)$, and as an activator positively regulating the efflux systems encoded by $c z r C B A$ and $z n t A$. Importantly, the highly expressed TonB dependent transporters ZnuK and ZnuL were shown to be essential for growth under zinc starvation, acting as key zinc scavenging systems. It was observed that Zur plays a significant role in keeping zinc homeostasis, since its absence lead to an alteration in the expression of some genes belonging to the Fur regulon. This is probably due to the unbalance in zinc intracellular concentration, which may cause further effects in other metal responsive regulatory systems. Further studies will be carried out in order to establish the whole regulatory network in response to metal availability in $C$. crescentus.

\section{Methods}

\section{Bacterial strains and growth conditions}

C. crescentus NA1000 wild-type strain and its derivative strains MM69 ( $\Delta z u r)$, MM72 (znuK::mini-Tn5 Km2), MM73 (znuL::mini-Tn5 Km2) and MM78 (CC0815:: mini- $\mathrm{Tn} 5 \mathrm{Km} 2$ ) were grown at $30^{\circ} \mathrm{C}$ under agitation in minimal medium M2 [46] and, when necessary, supplemented with tetracycline $\left(1 \mu \mathrm{g} \mathrm{ml}{ }^{-1}\right)$, kanamycin 
(5 $\mu \mathrm{g} \mathrm{ml} \mathrm{gl}^{-1}$ ) or nalidixic acid $\left(20 \mu \mathrm{g} \mathrm{ml}^{-1}\right)$. MM72, MM73 and MM78 strains were obtained from a mutant library generated by mini-Tn $5 \mathrm{Km} 2$ transposon insertion [31] and in the present study these mutations were individually transduced into a fresh C. crescentus NA1000 background. Complementation of the mutations was obtained by introduction of the low copy plasmid pMR20 [47] carrying either znuK or znuL. Zinc depletion and abundance were obtained by supplementing media with ethylenediamine tetraacetic acid (EDTA) or $\mathrm{ZnCl}_{2}$, respectively, as specified in each experiment. E. coli strains were grown at $37^{\circ} \mathrm{C}$ under agitation in Luria-Bertani (LB) or M9 media and, when necessary, supplemented with tetracycline $\left(12.5 \mu \mathrm{g} \mathrm{ml}^{-1}\right)$ or kanamycin $\left(50 \mu \mathrm{g} \mathrm{ml}^{-1}\right)$. All plasmids were introduced into Caulobacter strains via conjugation with E. coli strain S17-1 [48].

\section{Construction of zur mutant strain and complementation}

A zur mutant strain was obtained by allelic replacement in strain NA1000. Two 920-bp DNA fragments upstream and downstream from CC0357 [GenBank: AAK22344] respectively were cloned in tandem into the suicide vector pNPTS138 (a kind gift of D. Alley), and the construction was used for deletion of zur, generating strain MM69. Gene deletion was confirmed by both PCR and Southern blotting (not shown). Complementation of the zur mutation was obtained by introduction of plasmid pUJ142 [49] carrying an 1110-pb DNA fragment containing the $z u r$ gene.

\section{RNA extraction and DNA microarray analysis}

RNA purification from C. crescentus NA1000 and MM69 strains was carried out from $50 \mathrm{ml}$ midlog phase cultures grown in $\mathrm{M} 2$ medium supplemented with $200 \mu \mathrm{M} \mathrm{Z \textrm {ZnCl } _ { 2 }}$ for $1 \mathrm{~h}$. Total RNA was extracted using Trizol Reagent (Invitrogen), according to the manufacturer's instructions and residual chromosomal DNA contamination was removed by RNase-free DNase I (Fermentas) treatment followed by precipitation using sodium acetate and ethanol. Purified RNA underwent spectrophotometric quantification and visualization on formaldehyde agarose gels. RNA samples isolated from three independent bacterial cultures for each strain were used for DNA microarray analysis.

The DNA microarray experiments were performed as described in [27], using a custom-designed DNA oligo array (Agilent Technologies). The arrays contain 9-11 probes covering the region around the start codon $(-300$ to +200 ) of each predicted ORF in the genome of $C$. crescentus CB15. The four last probes for each gene, which correspond to the beginning of the translated region, were the ones considered for the expression analysis. Briefly, cDNA was generated from $12.5 \mu \mathrm{g}$ of total RNA and labeled with either $\mathrm{Cy} 3$ or $\mathrm{Cy} 5$ fluorescent dyes using the FairPlay III Microarray Labeling System (Stratagene). Labeled cDNA samples were hybridized to the probes, the arrays were scanned with an Agilent High Resolution Microarray Scanner and the data were extracted and normalized with the Feature Extraction Software 9.0 (Agilent). The values for the relative expression of each gene were the average of the values of its four last probes in all three biological replicates. We included as differentially expressed genes (Table 1) those that meet the following criteria: a minimum of 2-fold expression change for at least three probes in at least two biological replicates. The microarray data have been deposited in the Gene Expression Omnibus (GEO) database (http://www.ncbi.nlm.nih.gov/geo/) under accession number GSE57136.

\section{$\beta$-Galactosidase activity assays}

Zur and zinc-dependent gene regulation were determined using transcriptional fusions of promoters with the lacZ reporter gene in pRKlacZ290 plasmid [50]. Regulatory regions of the CC0214, CC0320, CC1517 genes were amplified by PCR using primers $0214-1$ (5' GGAATTCTTCGCGCGCCGAAAGTGAC-3') and 02142 (5' -CGGATCCAACCACGAGATGCGCGGTC-3'), Pcc 0320F (5'-TATGAATTCTCGAGCTTTTCGACCACCA GC-3') and Pcc0320R (5' -TATGGATCCCGACCAGCA CGAACGGCAGC-3'), 1517-1 (5'-GGAATTCGCCTT GTTGATCTCGTCAG-3') and 1517-2 (5'-GGATCCGT CTGGATCTCACTGGAGAA-3'), respectively. These PCR products were cloned into pGEM-T Easy, sequenced and subcloned as EcoRI/BamHI fragments into pRKlacZ290. The promoter region of CC0663 was obtained by subcloning a 512-bp EcoRI/BamHI fragment from pNPTS138 $\operatorname{cspB}$ [51] into pRKlacZ290. The CC1518 promoter fusion was obtained by inverting the fragment cloned into pRKlacZ290 from CC1517. The CC2720 promoter fusion was already available [29]. These fusions were introduced into NA1000 and MM69 strains by conjugation. Cultures were grown in M2 medium up to an optical density of 0.4 , supplemented with either 500 $\mu \mathrm{M}$ of $\mathrm{ZnCl}_{2}, 500 \mu \mathrm{M}$ of EDTA or $500 \mu \mathrm{M}$ of both, and then incubated for 2 hours. Gene expression was measured by determining $\beta$-galactosidase activity as described by [52].

\section{In silico analysis of Zur binding sites}

Four Zur-binding motifs described for different proteobacteria $[08,22,32,33]$ were aligned in order to identify conserved sequences, which were in turn used to perform a genome-scale screening for putative Zurbinding sites in the $C$. crescentus genome sequence in the RSAT website [53]. Additionally, promoter regions of Zur-regulated genes, identified by microarray analysis, were searched for conserved DNA motifs, using 
the MEME tool [54]. Sequence logos were generated using WebLogo [55].

\section{Site-directed mutagenesis}

Site-directed mutagenesis of the CC2720 promoter region was performed using primers CC2720-F (5'GCGATTGGCTAACG-3') and CC2720-Zur-boxmut-R (5'-AATCTGTTACTTCGCGGTTGCGCGCCGCGCG-3'), CC2720-Zur-boxmut-F (5'-CGCGCGGCGCGCAACCGC GAAGTAACAGATT-3') and CC2720-R (5'-GACCAACG CAACCAAG-3') as described previously for Fur-box mutagenesis [26]. The resulting 500-bp PCR products were cloned into pGEM-T Easy, sequenced to confirm substitution of GTAA by ACCG nucleotides in the Zur-binding site, and subcloned as EcoRI/BamHI fragment into pRKlacZ290. This construction was then used for $\beta$ galactosidase activity assays.

\section{Zur protein expression and purification}

The C. crescentus zur coding region was amplified from genomic DNA by PCR, using primers Zur-expresstag1 encoding a 5'-FLAG sequence (5' - TTCATATGGATTA CAAGGATGACGATGACAAGATGAGCATGGCCAAC GCTCCC-3')/Zur-express2 (5'-TTGGATCCTCAGCTTCG GCAATCCGCGC-3'), and the 419-bp NdeI/BamHI fragment was cloned into pET28a plasmid (Novagen). This construction was introduced into E. coli BL21(DE3) strain and His-FLAG-Zur protein expression was induced for $3 \mathrm{~h}$ with 0.5 -mM IPTG added to midlog cultures grown at $30^{\circ} \mathrm{C}$ in $\mathrm{M} 9$ medium. The recombinant protein was purified from soluble extract by NTA-resin affinity chromatography (Qiagen).

\section{Electrophoretic mobility shift assay (EMSA)}

PCR fragments containing the promoters of selected genes CC0214, CC0320, CC0663, CC1517/CC1518 were purified and labeled with [ $\gamma$-32P]-ATP using T4 Polynucleotide Kinase (Fermentas). Unincorporated nucleotides were removed with Qiaquick PCR purification kit (Qiagen). DNA binding was performed in a $20 \mu \mathrm{l}$ reaction in binding buffer $(10 \mathrm{mM}$ Tris- $\mathrm{HCl} \mathrm{pH} \mathrm{7.5,} 40 \mathrm{mM}$ $\mathrm{KCl}, 1 \mathrm{mM} \mathrm{MgCl}, 1 \mathrm{mM}$ dithiothreitol, $0.1 \mathrm{mM} \mathrm{MnCl}_{2}$, $0.1 \mathrm{mg} \mathrm{ml}^{-1}$ bovine serum albumin, $5 \%$ glycerol), containing salmon sperm DNA $\left(0.1 \mathrm{mg} \mathrm{ml}^{-1}\right)$, labeled DNA probes and increasing amounts of purified His-FLAGZur protein $(0,25,50,100,200$ and $500 \mathrm{nM})$. In competition assays, a 30 -fold excess of cold probe was used to challenge each of the labeled probes. The probe containing the coding region of the stationary phase-induced gene $\operatorname{csp} D$ was used as the non-specific competitor. After incubation at $30^{\circ} \mathrm{C}$ for $30 \mathrm{~min}$, the samples were loaded onto a native $4 \%, 5 \%$ or $8 \%$ polyacrylamide gels (depending on probe size) in $40 \mathrm{mM}$ Tris-acetate buffer $\mathrm{pH} 8.0$ (with no added EDTA), containing $2 \mathrm{mM} \mathrm{MnCl}_{2}$.
Gels were dried and radioactive species were detected by autoradiography.

\section{Measurement of zinc content in cell}

Overnight cultures were diluted to OD 0.1 in $500 \mathrm{ml} \mathrm{M} 2$ medium and incubated at $30^{\circ} \mathrm{C}$ under agitation. When cultures reached OD 0.4, $200 \mu \mathrm{M} \mathrm{ZnCl}{ }_{2}$ was added and cultures were incubated for further $2 \mathrm{~h}$. Cells from cultures were harvested and washed twice with wash buffer (0.5 $\mathrm{g} \mathrm{l}^{-1} \mathrm{Na}_{2} \mathrm{PO}_{4}, 1.74 \mathrm{~g} \mathrm{l}^{-1} \mathrm{KH}_{2} \mathrm{PO}_{4}$ and $1.06 \mathrm{~g} \mathrm{l}^{-1}$ $\mathrm{NH}_{4} \mathrm{Cl} \mathrm{pH}$ 6.9) containing $500 \mu \mathrm{M}$ EDDS (Sigma) to remove externally bound or free remaining zinc. After washes, cultures were harvested, dried and then metal content was determined by Inductively Coupled Plasma Optical Emission Spectrometry (ICP-OES) method, normalized to dry mass.

\section{Phenotypic characterization of znuK and znuL mutants under zinc starvation}

To determine the effect of zinc starvation on viability of NA1000, MM69, MM72, MM73 and MM78 strains, they were grown in $\mathrm{M} 2$ medium at $30^{\circ} \mathrm{C}$ up to midlog phase (OD600 $\mathrm{nm} \mathrm{0.6)} \mathrm{and} \mathrm{aliquots} \mathrm{were} \mathrm{taken} \mathrm{for} \mathrm{serial}$ dilutions. $20 \mu \mathrm{l}$-aliquots of a $10^{-5}$ dilution were spread on four M2 agar plates, containing either $500 \mu \mathrm{M}$, $850 \mu \mathrm{M}$ EDTA, $850 \mu \mathrm{M}$ EDTA plus $1.7 \mathrm{mM} \mathrm{ZnCl}_{2}$ or no additions. Plates were incubated for $72 \mathrm{~h}$ or $120 \mathrm{~h}$ and then photographed.

\section{Additional file}

Additional file 1: Figure S1. Amino acid alignment of $C$. crescentus Zur with other regulators of the Fur family.

\section{Competing interests}

The authors declare that they have no competing interests.

\section{Authors' contributions}

RRM and MVM planned the experiments and analyzed the data; RRM performed all genetic and gene expression studies, and protein-DNA interaction experiments. VSB carried out the viability tests. JFSN analyzed the microarray data. MVM participated in the design of the study and coordination. All authors helped to prepare the manuscript, read and approved the final manuscript.

\section{Acknowledgements}

This work was supported by São Paulo Research Foundation (FAPESP) and Conselho Nacional de Desenvolvimento Científico e Tecnológico (CNPq-Brasil). During the course of this work, RRM was supported by a postdoctoral fellowship grant 2011/18847-4 from FAPESP and MVM was partially supported by a fellowship grant 306558/2013-0 from CNPq-Brasil.

\section{Author details}

'Departamento de Microbiologia, Instituto de Ciências Biomédicas, Universidade de São Paulo, Av. Prof. Lineu Prestes 1374, 05508-900 São Paulo, Brazil. ${ }^{2}$ Departamento de Biologia Celular e Molecular e Bioagentes Patogênicos, Faculdade de Medicina de Ribeirão Preto, Universidade de São Paulo, Av. Bandeirantes, 3900, Ribeirão Preto, 14049-900 São Paulo, Brazil.

Received: 6 May 2014 Accepted: 21 August 2014

Published: 28 August 2014 


\section{References}

1. Blencowe DK, Morby AP: Zn(II) metabolism in prokaryotes. FEMS Microbiol Rev 2003, 27:291-311.

2. Braymer JJ, Giedroc DP: Recent developments in copper and zinc homeostasis in bacterial pathogens. Curr Opin Chem Biol 2014, 19:59-66.

3. Hantke K: Bacterial zinc uptake and regulators. Curr Opin Microbiol 2005, 8:196-202.

4. Hantke K: Bacterial zinc transporters and regulators. Biometals 2001, $14: 239-249$

5. Lee JW, Helmann JD: Functional specialization within the Fur family of metalloregulators. Biometals 2007, 20:485-499.

6. Brocklehurst KR, Hobman JL, Lawley B, Blank L, Marshall SJ, Brown NL, Morby AP: ZntR is a Zn(II)-responsive MerR-like transcriptional regulator of zntA in Escherichia coli. Mol Microbiol 1999, 31:893-902.

7. Busenlehner LS, Pennella MA, Giedroc DP: The SmtB/ArsR family of metalloregulatory transcriptional repressors: structural insights into prokaryotic metal resistance. FEMS Microbiol Rev 2003, 27:131-143.

8. Huang D, Tang D, Liao Q, Li H, Chen Q, He Y, Feng J, Jiamg B, Lu G, Chen B, Tang J: The Zur of Xanthomonas campestris functions as a repressor and an activator of putative zinc homeostasis genes via recognizing two distinct sequences within its target promoters. Nucleic Acids Res 2008 36:4295-4309.

9. Schröder J, Jochmann N, Rodionov DA, Tauch A: The Zur regulon of Corynebacterium glutamicum ATCC 13032. BMC Genomics 2010, 11:12.

10. Teramoto $\mathrm{H}$, Inui M, Yukawa $\mathrm{H}$ : Corynebacterium glutamicum Zur acts as a zinc-sensing transcriptional repressor of both zinc-inducible and zincrepressible genes involved in zinc homeostasis. FEBS Journal 2012, 279:4385-4397.

11. Stork M, Bos MP, Jongerius I, de Kok N, Schilders I, Weynants VE, Poolman JT, Tommassen J: An outer membrane receptor of Neisseria meningitidis involved in zinc acquisition with vaccine potential. PLOS Pathog 2010, 6:e1000969.

12. Stork M, Grijpstra J, Bos MP, Mañas Torres C, Devos N, Poolman JT, Chazin WJ, Tommassen J: Zinc piracy as a mechanism of Neisseria meningitidis for evasion of nutritional immunity. PLOS Pathog 2013, 9:e1003733.

13. Patzer SI, Hantke K: The ZnuABC high-affinity zinc uptake system and its regulator Zur in Escherichia coli. Mol Microbiol 1998, 28:1199-1210.

14. Moore CM, Helmann JD: Metal ion homeostasis in Bacillus subtilis. Curr Opin Microbiol 2005, 8:188-195.

15. Makui H, Roig E, Cole ST, Helmann JD, Gros P, Cellier MF: Identifification of the Escherichia coli K-12 Nramp orthologue (MntH) as a selective divalent metal ion transporter. Mol Microbiol 2000, 35:1065-1078.

16. Grass $G$, Wong MD, Rosen BP, Smith RL, Rensing C: ZupT is a Zn(II) uptake system in Escherichia coli. J Bacteriol 2002, 184:864-866.

17. Elvin CM, Dixon NE, Rosenberg H: Molecular cloning of the phosphate (inorganic) transport (pit) gene of Escherichia coli K12. Identification of the pitB gene product and physical mapping of the pit-gor region of the chromosome. Mol Gen Genet 1986, 204:477-484.

18. Rensing C, Mitra B, Rosen BP: The zntA gene of Escherichia coli encodes a Zn(II)-translocating P-type ATPase. Proc Natl Acad Sci U S A 1997 94:14326-14331.

19. Nies DH: The cobalt, zinc and cadmium efflux system CzcABC from Alcaligenes eutrophus functions as a cation-proton antiporter in Escherichia coli. J Bacteriol 1995, 77:2707-2712.

20. Xiong A, Jayaswal RK: Molecular characterization of a chromosomal determinant conferring resistance to zinc and cobalt ions in Staphylococcus aureus. J Bacteriol 1998, 180:4024-4029.

21. Feria MP, Thrash JC, Giovannoni SJ, Patrick WM: New rRNA Gene-Based Phylogenies of the Alphaproteobacteria Provide Perspective on Major Groups. Mitochondrial Ancestry and Phylogenetic Instability. PLoS One 2013, 8:e83383.

22. Li Y, Qiu Y, Gao H, Guo Z, Han Y, Song Y, Du Z, Wang X, Zhou D, Yang R: Characterization of Zur-dependent genes and direct Zur targets in Yersinia pestis. BMC Microbiol 2009, 9:128.

23. Yang X, Becker T, Walters N, Pascual DW: Deletion of znuA virulence factor attenuates Brucella abortus and confers protection against wild-type challenge. Infect Immun 2006, 74:3874-3879.

24. Curtis PD, Brun YV: Getting in the loop: regulation of development in Caulobacter crescentus. Microbiol Mol Biol Rev 2010, 74:13-41.

25. Nierman WC, Feldblyum TV, Laub MT, Paulsen IT, Nelson KE, Eisen JA, Heidelberg JF, Alley MR, Ohta N, Maddock JR, Potocka I, Nelson WC,
Newton A, Stephens C, Phadke ND, Ely B, DeBoy RT, Dodson RJ, Durkin AS, Gwinn ML, Haft DH, Kolonay JF, Smit J, Craven MB, Khouri H, Shetty J, Berry K, Utterback T, Tran K, Wolf A, Vamathevan J, Ermolaeva M, White O, Salzberg SL, Venter JC, Shapiro L, Fraser CM: Complete genome sequence of Caulobacter crescentus. Proc Natl Acad Sci U S A 2001, 98:4136-4141.

26. da Silva Neto JF, Braz VS, Italiani VCS, Marques MV: Fur controls iron homeostasis and oxidative stress defense in the oligotrophic alphaproteobacterium Caulobacter crescentus. Nucleic Acids Res 2009, 37:4812-4825

27. da Silva Neto JF, Lourenço RF, Marques MV: Global transcriptional response of Caulobacter crescentus to iron availability. BMC Genomics 2013, 14:549.

28. Braz VS, da Silva Neto JF, Italiani VCS, Marques MV: CztR, a LysR-Type Transcriptional Regulator Involved in Zinc Homeostasis and Oxidative Stress Defense in Caulobacter crescentus. J Bacteriol 2010, 192:5480-5488.

29. Valencia EY, Braz VS, Guzzo C, Marques MV: Two RND proteins involved in heavy metal efflux in Caulobacter crescentus belong to separate clusters within proteobacteria. BMC Microbiol 2013, 13:79.

30. McGrath PT, Lee $H$, Zhang L, Iniesta AA, Hottes AK, Tan MH, Hillson NJ, Hu $P$, Shapiro L, McAdams HH: High-throughput identification of transcription start sites, conserved promoter motifs and predicted regulons. Nat Biotechnol 2007, 25:584-592.

31. Braz VS, Marques MV: Genes involved in cadmium resistance in Caulobacter crescentus. FEMS Microbiol Lett 2005, 251:289-295.

32. Pawlik MC, Hubert K, Joseph B, Claus H, Schoen C, Vogel U: The zincresponsive regulon of Neisseria meningitidis comprises 17 genes under control of a Zur element. J Bacteriol 2012, 194:6594-6603.

33. Lim CK, Hassan KA, Penesyan A, Loper JE, Paulsen IT: The effect of zinc limitation on the transcriptome of Pseudomonas protegens Pf-5. Environ Microbiol 2012, 15:702-715.

34. Mills SA, Marletta MA: Metal binding characteristics and role of iron oxidation in the ferric uptake regulator from Escherichia coli. Biochem 2005, 44:13553-13559.

35. Ma Z, Faulkner MJ, Helmann JD: Origins of Specificity and Crosstalk in Metal Ion Sensing by Bacillus subtilis Fur. Mol Microbiol 2012, 86:1144-1155.

36. Pohl E, Haller JC, Mijovilovich A, Meyer-Klaucke W, Garman E, Vasil ML: Architecture of a protein central to iron homeostasis: crystal structure and spectroscopic analysis of the ferric uptake regulator. Mol Microbiol 2003, 47:903-915

37. Ma Z, Lee JW, Helmann JD: Identification of altered function alleles that affect Bacillus subtilis PerR metal ion selectivity. Nucleic Acids Res 2011, 39:5036-5044

38. Gaballa A, Wang T, Ye RW, Helmann JD: Functional analysis of the Bacillus subtilis Zur regulon. J Bacteriol 2002, 184:6508-6514

39. Gabriel SE, Helmann JD: Contributions of Zur-controlled ribosomal proteins to growth under zinc starvation conditions. J Bacterio/ 2009 191:6116-6122.

40. Maciag A, Dainese E, Rodriguez GM, Milano A, Provvedi R, Pasca MR, Smith I, Palù G, Riccardi G, Manganelli R: Global analysis of the Mycobacterium tuberculosis Zur (FurB) regulon. J Bacteriol 2007, 189:730-740.

41. Panina EM, Mironov AA, Gelfand MS: Comparative genomics of bacterial zinc regulons: enhanced ion transport, pathogenesis, and rearrangement of ribosomal proteins. Proc Natl Acad Sci U S A 2003, 100:9912-9917.

42. Haas CE, Rodionov DA, Kropat J, Malasarn D, Merchant SS, de Crécy-Lagard $V$ : A subset of the diverse COG0523 family of putative metal chaperones is linked to zinc homeostasis in all kingdoms of life. BMC Genomics 2009, $10: 470$

43. Nies DH: Efflux-mediated heavy metal resistance in prokaryotes. FEMS Microbiol Rev 2003, 27:313-339.

44. Schauer K, Rodionov DA, de Reuse H: New substrates for TonB-dependent transport: do we only see the 'tip of the iceberg'? Trends Biochem Sci 2008, 33:330-338.

45. Schauer K, Gouget B, Carrière M, Labigne A, de Reuse H: Novel nickel transport mechanism across the bacterial outer membrane energized by the TonB/ExbB/ExbD machinery. Mol Microbiol 2007, 63:1054-1068.

46. Ely B: Genetics of Caulobacter crescentus. Methods Enzymol 1991, 204:372-384.

47. Roberts RC, Toochinda C, Avedissian M, Baldini RL, Gomes SL, Shapiro L: Identification of a Caulobacter crescentus operon encoding hrcA, involved in negatively regulating heat-inducible transcription and the chaperone gene grpE. J Bacteriol 1996, 178:1829-1841. 
48. Simon R, Priefer U, Pühler A: A broad host range mobilization system for in vivo genetic engineering: transposon mutagenesis in Gram negative bacteria. Nat Biotechnol 1983, 1:784-791.

49. Meisenzahl AC, Shapiro $L$, Jenal $U$ : Isolation and characterization of a xylose-dependent promoter from Caulobacter crescentus. J Bacteriol 1997, 179:592-600.

50. Gober JW, Shapiro L: A developmentally regulated Caulobacter flagellar promoter is activated by 30 enhancer and IHF binding elements. Mol Biol Cell 1992, 3:913-916.

51. Mazzon RR, Lang EAS, da Silva CAPT, Marques MV: Cold Shock Genes cspA and $\operatorname{csp} B$ from Caulobacter crescentus are posttranscriptionally regulated and important for cold adaptation. J Bacteriol 2012, 194:6507-6517.

52. Miller JH: Experiments in molecular genetics: A laboratory manual. Cold Spring Harbor, NY: Cold Spring Harbor Laboratory Press; 1972.

53. Thomas-Chollier M, Defrance M, Medina-Rivera A, Sand O, Herrmann C, Thieffry D, van Helden J: RSAT 2011: regulatory sequence analysis tools. Nucleic Acids Res 2011, 39:W86-W91.

54. Bailey TL, Elkan C: Fitting a mixture model by expectation maximization to discover motifs in biopolymers. In Proceedings of the Second International Conference on Intelligent Systems for Molecular Biology: August 1994. Edited by Altman RB, Brutlag DL, Karp PD, Lathrop RH, Searls DB. Menlo Park, CA: AAAI Press; 1994:28-36.

55. Crooks GE, Hon G, Chandonia JM, Brenner SE: WebLogo: a sequence logo generator. Genome Res 2004, 14:1188-1190.

doi:10.1186/1471-2164-15-734

Cite this article as: Mazzon et al:: Analysis of the Caulobacter crescentus Zur regulon reveals novel insights in zinc acquisition by

TonB-dependent outer membrane proteins. BMC Genomics 2014 15:734.

\section{Submit your next manuscript to BioMed Central and take full advantage of:}

- Convenient online submission

- Thorough peer review

- No space constraints or color figure charges

- Immediate publication on acceptance

- Inclusion in PubMed, CAS, Scopus and Google Scholar

- Research which is freely available for redistribution 